\title{
MODERNAS LIGAS METÁLICAS EM ODONTOLOGIA *
}

\author{
** LUIZ ANTONIO RUHNKE
}

\section{1. "OURO COESIVO"}

Embora não seja propriamente uma liga, mereceu de nossa parte a devida atenção, uma vez que tem havido grandes modificações tecnológicas com referência ao ouro para restaurações diretas.

Os documentos históricos que abordam as antigas civilizações, conı as dos Incas e dos Maias, e mesmo a dos antepassados europeus, nos relatam que o ouro puro foi empregado em trabalhos odontológicos rudimentares, quer como função terapêtica ou ornamental.

Entretanto, mais recentemente, o ouro puro, em forma de lâmina, conhecido como "ouro coesivo" foi am plamente utilizado na Odontologia Moderna para confecção de restaurações odontológicas.

Graças à propriedade de soldarse em condições normais de temperatura e umidade, o ouro puro pocie ser condensado ou compactado, lâmina sobre lâmina, porção sobre por. ção, numa cavidade dental. Essa ca. racterística confere ao ouro coesivo a propriedade de ser considerado o restaurador "ideal", porém, o seu uso tem sido limitado por diversos fatores, destacando-se a sua cor, alto coeficiente de condutibilidade térmica, dificuldade de manipulação, e pouca dureza (1).
Presentemente existe no mercado à disposição dos profissionais três tipos de ouro para restauração denlal direta, que são: ouro em folha, ouro eletrolítico e ouro em pó (2).

O ouro em folha é simplesmento uma lâmina finíssima de ouro puro, 99,99 , lisa ou corrugada, com a espessura de 6,4 micrômetro.

A classificação do ouro coesivo em folha, é geralmente feita por nú. mero que corresponde ao peso em grama, de uma lâmina de $2.580 \mathrm{mm:}$ ou 4 polegadas quadradas. Assim uma lâmina n. $^{\circ} 4$ deve pesar 4 grama, n. ${ }^{\circ}$ 6, 6 grama, etc.

Essas lâminas podem ser enroladas formando pequenos cilindros para facilitar a condensação na cavidade.

Outra forma de ouro puro, empregado para restaurações diretas, é chamada de ouro eletrolítico ou "mat gold'. Um pó formado por precipitação eletrolítica, é comprimido e transformado em tira e aquecido a uma temperatura inferior ao ponto de fusão. As partículas de pó são dessa forma unidas, e esse processo é conhecido como siterização.

O ouro eletrolítico pode ser colocado diretamente na cavidade ou envolto por lâminas e condensado na cavidade.

O ouro em pó, constitui outro tipo de ouro coesivo, é obtido por precipitação química, ou atomização do metal fundido. Essas partículas são 
muito pequenas e um conglomerado delas é condensado na cavidade.

o conglomerado é geralmente preparado com a utilização de álcool ou fenol diluído. $O$ conglomerado é colocado na cavidade e compactado. Também é encontrado no comércio na forma de pastilha bastante frouxa. Uma das vantagens apresentada pelo ouro em pó é a sua densidade por uni. dade de volume (3).

\section{LIGAS DE OURO PARA RESTAURAÇõES}

Muitas das ligas de ouro para restaurações fundidas, eram no passado, formuladas de modo bastante empirico.

As ligas de ouro usadas atualmente em Odontologia são compostas de ouro, prata e cobre, com algumas modificações em que estão presentes platina, paládio e zinco, dependendo do tipo.

Atualmente temos 4 tipos de ligas de ouro, as quais são classificadas pela especificação n. ${ }^{0} 5$ e 7 da A.D.A. São classificadas quanto à dureza, pois essa propriedade possui intima relação com as demais. Segundo as especificações acima citadas, os quatro tipos são: mole, médio, dura e extra-dura.

Muitas das ligas de ouro usadas em odontologla, podem ser endurecidas com apropriado tratamento térmico, para controle de dureza.

As ligas que contêm grandes quantidades de ouro e metais do grupo paládio (tipos I e II) apresentam baixa dureza e respondem muito pouco aos tratamentos térmicos.
As ligas dos tipos IV e $\mathrm{V}$, dura e extra-dura, respondem muito bem aos tratamentos térmicos. Elas po. dem ser amaciadas com resfriamen'o a partir de $700^{\circ} \mathrm{C}$. O tratamento enaurecedor é conseguido resfriando-se a liga uniformemente, de 450 para $250^{\circ} \mathrm{C}$ durante 30 minutos. Obtém-se assim aumento de dureza e resistência, porém a dutilidade é sensivelmente reduzida.

Todas as ligas apresentam uma característica negativa, qual seja contração de solidificação.

Lane, Hollenback e Skinner (4 e 6), identificaram a contração linear das ligas entre 1,0 a $2,2 \%$.

A forma e o tamanho dos corpos de prova, a composição da liga e a técnica de fundição são três fatores influentes na amplitude das contrações. O valor de $1,4 \pm 0,2 \%$ é considerado valor médio das contrações das I:gas de ouro.

Skinner (6), Nielsen e Tuccillo (5) estudando o tamanho dos grãos cristalinos das ligas de ouro notaram que as ligas, cujos grãos cristalinos eram menores, possuiam melhores propriedades que as ligas com grãos crist. $x^{-}$ linos maiores. A diminuição dos grãos aumenta a resistência à tração e a elongação em cerca de $30 \%$ como afirmava Skinner. O aumento de $100 \%$ no número de grãos cristalinos por unidade de volume pode ser obtido com adição de $50 \mathrm{ppm}$ de rutênio ou irídio.

Embora os valores de resistência à tração e elongação sejam aumentados nas ligas de grãos finos a quantidade de segregação é a mesma nos dois tipos de ligas. 
De certa forma pouca novidade existe a respeito das ligas de ouro para fundição.

Diversos fabricantes colocam hoje no mercado excelentes ligas de ouro para todos os tipos de trabalhos, e os mais conceituados, são a. quelas que constam das relações di. vulgadas pela ASSOCIACCAO DENTA. RIA AMERICANA. Em nosso país já existem diversos fabricantes que nos oferecem excelentes ligas para as mais variadas indicações, procurando sempre enquadrar seus produtos nas especificações do G.B.M.D.

\section{LIGAS PARA PORCELANA FUNDIDA}

A fusão de porcelana sobre metais ou ligas não é recente, pois os egípicios já conheciam esse tipo de trabalho.

A partir de 1950, os trabalhos com porcelana e metal tiveram grande desenvolvimento. Como todas os materiais e técnicas, quando de início, aprosentam fathas. Algumas vezes a porcelana sofrendo a influência da liga apresentava-se manchada e quebradi. ça por causa da diferença de expansão térmica entre a liga e a porcelana. Inicialmente a cor sofria alteração devido a materiais e técnicas.

O cobre das ligas produzia um: coloração verde,e a prata a cor mar ron.

Ligas de ouro dos tipos 1 e II não possuem características que permitam sua indicação para trabalhos com poncelana fundida.
0 emprego de tigas de alta fusão, com alto teor de paládio são mais recomendadas.

Gunnar Ryge ( 8 e 9), hos informa que com o desenvolvimento de novas técnicas e a produção de melhores materiais, a maioria das falhas têm $s$ :do reduzidas e os trabathos obtidus são cada vez melhores. O êxito está no uso correto da porcelana e da liga.

Muitas ligas têm sido experimentadas para 480 com porcelana, por exemplo, ligas à base de níquel ern que sua aplicação é limitada ao tipo de porcelana.

As ligas mais comumente usadas em trabalhos de porcelana são à base de oura e contêm de 8 a $15 \%$ de platina, acima de $5 \%$ de paládio, e também pequenas quantidades de ferro, iridio e estanho com $1 \%$, conforme nos informa Fairhurst (7).

0 irídio e o estanho contribuem para $\circ$ endurecimento da liga quando da fusão da porcelana. Em outras palavras, no momento em que a porcelana é fundida sobre a peça metá! ca, toda a liga sofre um tratamento térmico endurecedor.

A maioria das ligas à base de ouro endurecem durante o ciclo de reação da porcelana.

O mecanismo de endurecimento aparenta ser um processo de revenido, provocado pela ação de pequena quantidade de ferro, irídio e estanho em ligas de ouro platinado, quando da reação entre a platina e o ferro na temperatura de fusão (15-17).

As ligas à base de paládio que podem ser usadas com certo limite, em trabalhos de porcelana, são com- 
postas basicamente de paládio, prata e rutênio, segundo Ryge (9) e fundemse à temperatura mais altas do que as ligas à base de ouro. A resistência das ligas à base de paládio, deriva de sua composição e não são endurecidas por processo de revenido.

As ligas utilizadas em trabalhos com porcelana devem apresentar coe. ficiente de expansão térmica próxima do coeficiente da porcelana ou viceversa. Isso é extremamente necessário para reduzir a possibilidade 'de fratura da porcelana durante 0 seu resfriamento.

A união das porcelanas com as ligas tem se realizado de forma satisfatória, embora o mecanismo dessa união não esteja ainda completamente esclarecido. Há, portanto, divergências entre os pesquisadores, onde diversos como Ryge e O'Brien (8) afirmam ser a união porcelana e liga resultante de forças de Van der Waal.

Bandinelli acha que o óxido de estanho na superfície da base metalica combina com a porcelana produzindo a união e também que a pequena diferença entre as duas fases no tocante à expansão térmica resulta em forças de compressão.

A despeito de modernos métodos de análises, ainda não foi possível determinar o mecanismo da união liga e porcelana.

\section{LIGAS DE METAIS NOBRES}

Essas ligas são chamadas de !:gas de metais nobre. Alguns preferem o nome de baixo teor de ouro, ou ainda ligas de prata e paládio.
O professor Kamal Asgar, em recente visita nos forneceu relação dessas ligas, as mais evidentes, com características semelhantes.

Classificou-as em três grupos distintos. Classificação essa, baseada na composição:

Liga do tipo A:

- 40 a $45 \%$ de $\mathrm{Au} / 5$ a $6 \%$ $\mathrm{Pd}-\mathrm{Ag}$ e outros metais

Liga do tipo $B$ :

- 10 a $15 \%$ de Au; 18 a $20 \%$ $\mathrm{Pd}+\mathrm{Ag}$ e outros metais

Liga do tipo C:

- $0 \%$ Au 23 a $27 \%$ Pd e Ag.

Hawmedica (Vitalim) $\mathrm{Cr}-\mathrm{Ni}$

Aurolite (prata paládio)

Albacast (Jelenko)

Aborimn - Jelenko $10-15 \% \mathrm{Au}$

Forticast - Jelenko $45 \%$ Au.

A quantidade de ouro pode ser reduzida desde que seja substituída por prata ou cobre. Tuccilo e Meabron estudando as ligas de baixo teor de ouro apresentam uma composição que pode ser utilizada sem maiores problemas. Essa liga tem a seguinte composição:

$\begin{array}{ccccc}\mathrm{Au} & \mathrm{Pd} & \mathrm{Ag} & \mathrm{Cu} & \mathrm{Ag} / \mathrm{Cu} \\ 45 & 6 & 30 & 19 & 1.4-2 \%\end{array}$

Phillips ao estudar as ligas indicadas para substituir as de ouro diz que a liga apresentada por Tuccillo e Nealson é bastante resistente a manchas e perda de brilho, tanto quanto as ligas de ouro constantes das especificaçōes da ADA. Essa liga possue coloração amarela, apresenta características de fundição idênticas às das ligas de ouro e é facilmente soldada com outras ligas próprias. Ain- 
da de acordo com Phillips, pode ser classificada de substituta das ligas da ouro.

As três composições relacionadas anteriormente, apresentam custos $13 \%$, $20 \%$ e $25 \%$ menores que as de ouro.

Em algumas faculdades nacionais já estão sendo utilizadas em trabaIhos de policlínicas ligas de baixo teor de ouro.

\section{LIGAS DE CROMO-COBALTO}

As ligas de Cr-Co, são chamadas por alguns autores de superligas devido a sua resistência e estabilidade a altas temperaturas.

Outros autores as chamam de Stellitas por causa de sua resistência à corrosão. Desde 1930 que as mesmas têm sido usadas pelos dentistas, mas sempre com certa restrição, devido a fraturas durante esforços de dobramento. Ligas à base de Cobalto têm sido formuladas com propriedades próprias para usos Odontológicos.

As atuais ligas têm como matriz básica a seguinte composição: Cobalto $40 \%$, Niquel $30 \%$ e $\mathrm{Cr} 30 \%$.

As ligas de cromo-cobalto desde que foram apresentadas à Odontologia, têm conquistado muitos adeptos e principalmente na confecção de prótese removível.

Recentes desenvolvimentos na formulação de novas ligas têm contribuido para um aumento da sua utilização. Sua baixa densidade, baixo custo, alto módulo de elasticidade $e$ resistencia a manchas e perda de briIho comparada com as ligas de ouro.
Ligas semelhantes à utilizadas por nós dentistas, têm sido usadas para implantes ortopédicos. Implante em Odolontologia já foi tentado e com relativo sucesso.

Se por um lado o baixo custo das ligas de Cromo-Cobalto têm promovido o seu uso, por outro lado a necessidade de equipamentos e técnicas especiais têm dificultado, ficando restrito quase que inteiramente a laboratórios comerciais. Presentemente as ligas sofreram reformulação em sua composição (11). As ligas modernas contêm também carbono, molibdênio, alumínio, e algumas vezes ferro, silicio, tungstênio, manganês e berílio. Até platina foi colocada para melhorar a resistência à corrosão e aumentar a dutilidade, essa liga é a Platinore. Porém, muitas pesquisas estão senco feitas para estabelecer com exatidão a quantidade de platina responsável pelo aumento da dutilidade e resistência à corrosão.

Uma outra liga Nobiluim, contém pequena quantidade de gálio, o qual é responsabilizado pelo tamanho dos grãos cristalinos, durante o resfriamento.

Outras ligas têm sido propostas, como as que possuem grande quantidade de níquel e baixa quantidade de cobalto, além de metais como aluminio. Embora essas ligas não apresentassem fraturas em 18 meses de uso na boca, mostraram-se de menor resistência à perda de brilho (12).

O metal cobalto nessas ligas aparece apenas como traços. Nos Estados Unidos é conhecida como Ticonim Premium 100. Algumas dessas 
ligas chegam a ser recomendadas para trabalho com porcelana.

$\mathrm{Na}$ Europa, algumas ligas lá desenvolvidas, são bastante flexiveis e resistem a dobramentos muito mais que as ligas de Níquel-Cromo, porém a sua composição básica é Cromo, Cobalto e Molibdênio. Elas possuem tolerância biológica e alta resistência à corrosão (13).

$\mathrm{Na}$ Universidade de Michigam, foi desenvolvida uma liga com $26 \%$ 'de Cr., e os dados obtidos indicam que uma redução no conteúdo de molibdênio e Carbono, as proporiedades, como resistência à tração e dureza. são mantidas.

Civjan e outros (12), comparando as características das ligas de CromoCobalto com as de Cromo-Niquel. notaram que as ligas de Níquel apresentam melhores características de fundição e suas propriedades podem ser controladas por tratamento térmico.

As ligas de Cromo-Cobalto têm, a rigor, duas vezes mais flexibilidade do que as ligas de ouro. Isso significa que os grampos feitos com Cro. mo-Cobalto defletem mais do que os de ouro sob a mesma carga.

A resistência à tração mínima requerida para as ligas de cromo-co. balto é da ordem de $6.300 \mathrm{Kg} / \mathrm{cm}^{2}$. Essa resistência à tração é igual ou inferior ao das ligas de ouro (13).

Geralmente as ligas fraturam mass por causa da fadiga flexural. Algumas das novas ligas apresentadas no mercado apresentam resultados de elongação similar aos apresentados pelas ligas de ouro.
A estrutura metálica das ligas $\mathrm{Cr}-\mathrm{Co}$ e $\mathrm{Cr}-\mathrm{Ni}$ são basicamente diferentes. As ligas de Cr-Co são mais resistentes e endurecidas devido principalmente à presença de carbonetos. e no caso das ligas $\mathrm{Cr}-\mathrm{Ni}$ a resistência é devida a um composto intermetálico cuja fórmula é $\mathrm{Ni}_{3} \mathrm{Al}$, ou identificado como fase (gama).

A especificação da A.D.A. divide as ligas contendo cromo em dois tipos baseados na temperatura de iusão. $1300^{\circ} \mathrm{C}$ é o limite.

Acima dessa temperatura há ne. cessidade de revestimento especia!. A contração de fundição das ligas cie Cromo-Cobalto foi estabelecida por EARNSHAW (13) como sendo de 2.05 e $2.38 \%$.

Nas ligas de alto teor de níquel a contração é da ordem de $1,2 \%$.

A temperatura de fusão tem grande influência nas propriedades físicas.

Alta temperatura provoca modificações na microestrutura produzindo carbonetos de tamanho e forma diferentes da desejada, afetando principalmente o valor de elongação. A fonte de calor é fator influente.

Os valores das propriedades físicas também variam com 0 resfriamento da peça fundida. E recomendada a espera de 15 minutos antes de mergulhar em água.

As ligas de niquel-cromo podem ser amolecidas com tratamento adequado bem como endurecida com outro tratamento.

As sobras de ligas podem ser reaproveitados desde que fundidas com $50 \%$ de liga nova. 
As ligas de cromo-cobalto têm proporcionado excelentes trabalhos e seu emprego será sempre um sucesso desde que sejam observadas as suas características de desenho e técnicas.

Outras ligas de menor importâ. cia têm aparecido no mercado.
Todas elas são apresentadas coco substitutas das ligas de ouro.

Suas características não preenchem todos os requisitos mínimos para que as mesmas sejam empregadas em trabalhos Odontológicos, o que nos permite aguardar melhores estudos para que possamos aceitátas.

R. Fac. Odont. P. A. 


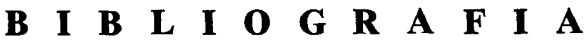

1. BAUM, Lloyd. Gold foil (filling golds) in dental practice. Dent. Clin. N. Amer., March 1965, p. 199.

2. LUND, M. R., and Baum, Lloyd. Powdered gold as a restorative material. J. Pros. Den. 13:1151 Nov. - Dec. 1963.

3. RICHTER, W. A., and Cantwell, K. R. A. study of cohesive gold. J. Pros. Den. 15:722 July - Aug. 1965.

4. HOLLENBACK, G. M., and Skinner, E. W. Shrinkage during casting of gold and gold alloys. JADA 33:1931 Nov. 1946.

5. NIELSEN, J. P., and Tuccillo, J. J. Grain size in cast gold alloys. J. Dent. Res. 45:964, May - June 1966.

6. SKINNER, E. W. Effect of nucleation of gold alloys. I. A. D. R. 45:188 March 1966 (abstract).

7. FAIRHURST, C. W., and Leinfelder, K. F. Heat treating porcelain-enameled restorations. J. Pros. Den. 16:554 May - June 1966.

8. LEINFELDER, K. F.; O'Brien, W. J.; Ryge, G.; and Fairhurst, C. W. Hardening of high-fusing gold alloys. J. Dent. Res. 45:392 March - April 1966.

9. RYGE, Gunnar. Current American research on porcelain-fused-to-metal restoratins. Int. Dent. J. 15:385 Sept. 1965.

10. ASGAR, K., and Peyton, F. A. Effect of casting conditions on some mechanical properties of cobalt-base alloys. J. Dent. Res. 40:73 Jan - Feb. 1961.

11. ASGAR, K.; Techow, B. O. and Jacobson, J. M. A. new alloy for partial dentures. J. Pros. Dent. 23:36 Jan. 1970.

12. CIVJAN, S.; Huget, E. F.; and Lichtenberger, H. Metallography of nickelchromium based dental alloys. IADR Abstracts 1970 Abstract 540, page 183.

13. EARNSHAW, R. Fatigue tests on a dental cobalt-chromium alloy, Brit. $D$. J. 110:341 May 16, 1961.

14. HARCOURT, H. J.; Riddihough, M./ and Osborne, J. The properties of nickel chromium casting alloys containing boron and silicon, Brit. D.J. 129:419 Nov. 3, 1970.

15. PAFFENBARGER, G. C.; Caul, H. L. L. and Dickson, George. Base metal alloys for oral restoratins. JADA 30:852 June 1943.

* Trabalho apresentado no Simpósio sobre Materiais Dentários, por ocasião do 4.0 Congresso Guanabarino e 4.0 Congresso Braslleiro da Fed. Nacional dos Odontologistas. Abril, 1975; Rio de Janeiro.

* Prof. Titular de Materiais Dentários, Fac. Odont. Piracicaba, Univ. de Campinas 